Diba Malekpour Koupaei ${ }^{1}$, Farzad Hashemi², Vinciane Tabard-Fortecoëf ${ }^{3}$ and Ulrike Passe ${ }^{1}$

1 lowa State University 2 Penn State University $\quad 3$ INSA Lyon

\title{
Representing Low-Income Households in Building Energy Modelling Tools
}

\section{PROBLEM STATEMENT}

In urban areas, low-income households experience a high energy burden and need to allocate a disproportionate share of their income to energy expenditures due to energy inefficiencies in their homes.

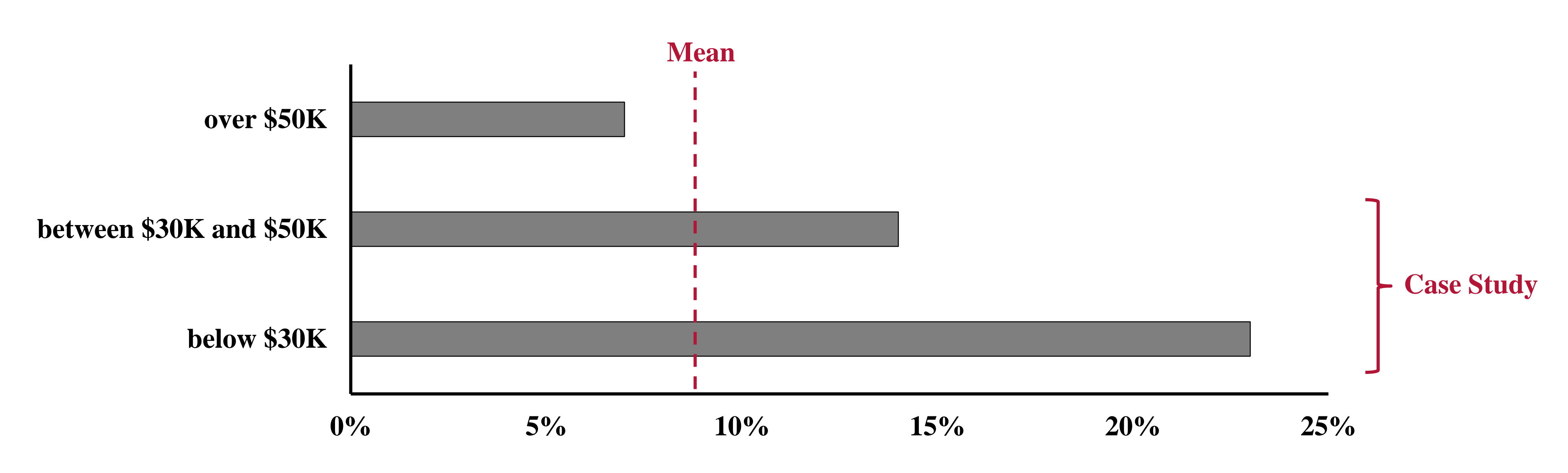

Estimated U.S. household energy costs as percentage of after-tax income

Thus, in the recent years improving the low-income housing stock and providing the residents with resources and/or incentives that would present a venue for a more sustainable future has been emphasized and promoted.
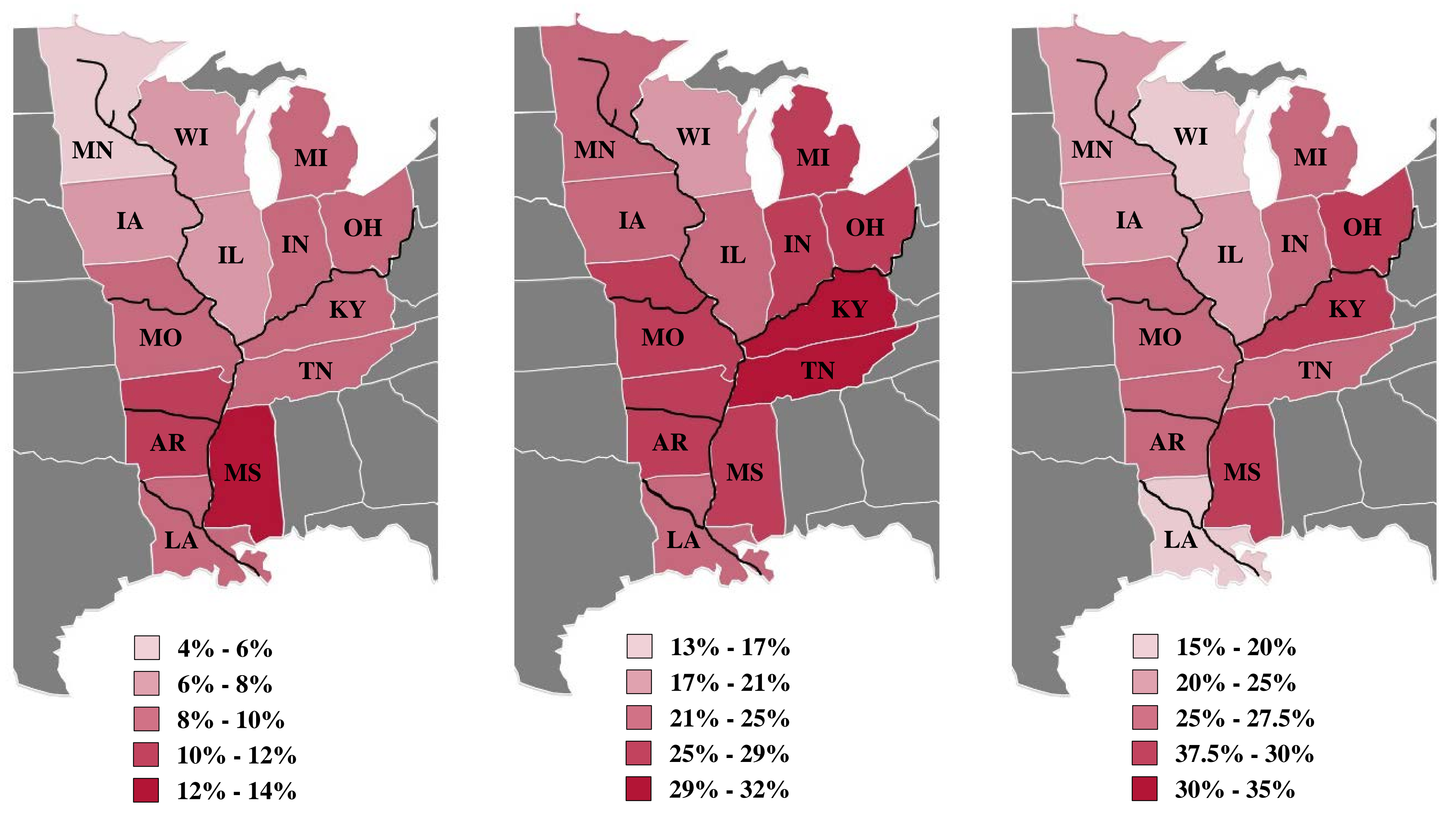

Left: Energy Burden (\% of Income) Middle: Potential Electricity Savings (\% of Baseline Consumption) Right: Potential Bill Savings (\% of Baseline Bill)

However, all parties involved in this process suffer from a lack of reliable data that is specific to low-income households and their unique characteristics.

\section{DESCRIPTION OF THE TECHNIQUE}

Building energy performance modelling tools provide a basis for informative decision making. However, such tools need occupancy related data to count for the effect of presence and activities of users on energy consumption and this need becomes challenging when little to no data is available for representing unique populations like low-income households.

Accordingly, in this study population-specific data collected via a mail survey is used to refine the results of a Markov-chain probabilistic occupancy prediction model based on the American Time-Use Survey (ATUS).

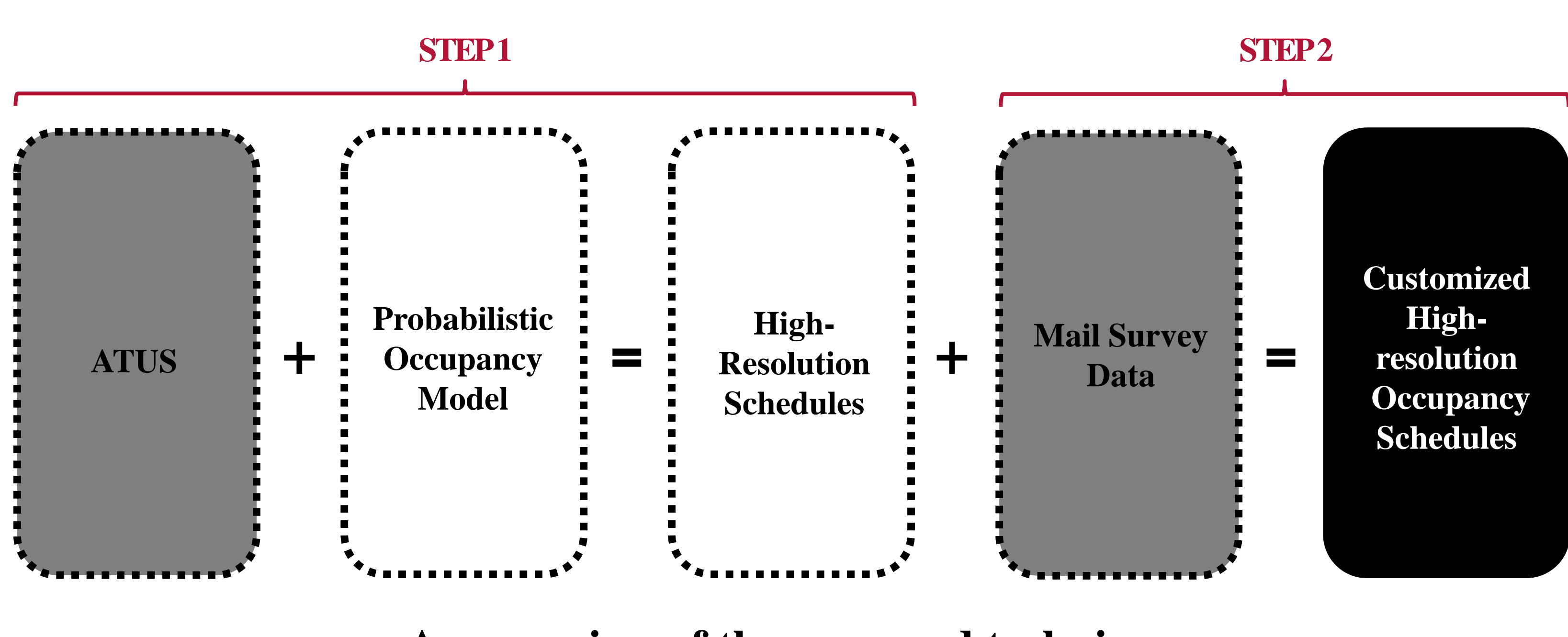
An overview of the proposed technique

This following question in the survey specifically addressed occupancy patterns:

"In an average week:

a. What percent of your Monday-Friday daytime hours is spent at home?

b. What percent of your Monday-Friday evening hours is spent at home?

c. What percent of your weekend daytime hours is spent at home?

d. What percent of your weekend evening hours is spent at home?"

This energy use survey was sent to about 1000 household addresses in three adjoining low-income neighborhoods (i.e., Capitol East, Capitol Park, and MLK Jr Park) in the Des Moines metropolitan area.

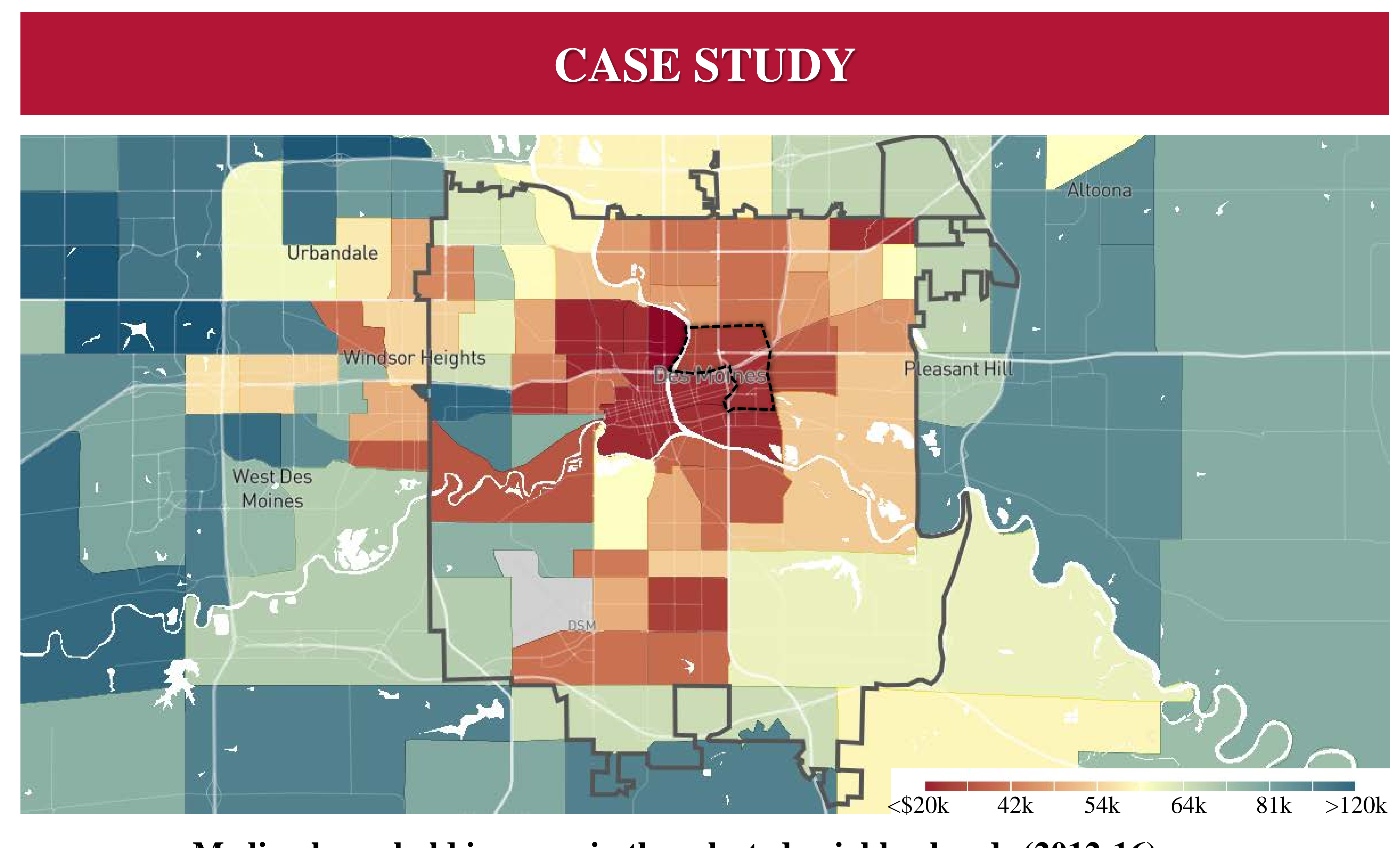

Median household incomes in the selected neighborhoods (2012-16)

Survey results were clustered into six representative groups and using the proposed technique, the following occupancy profiles were generated:
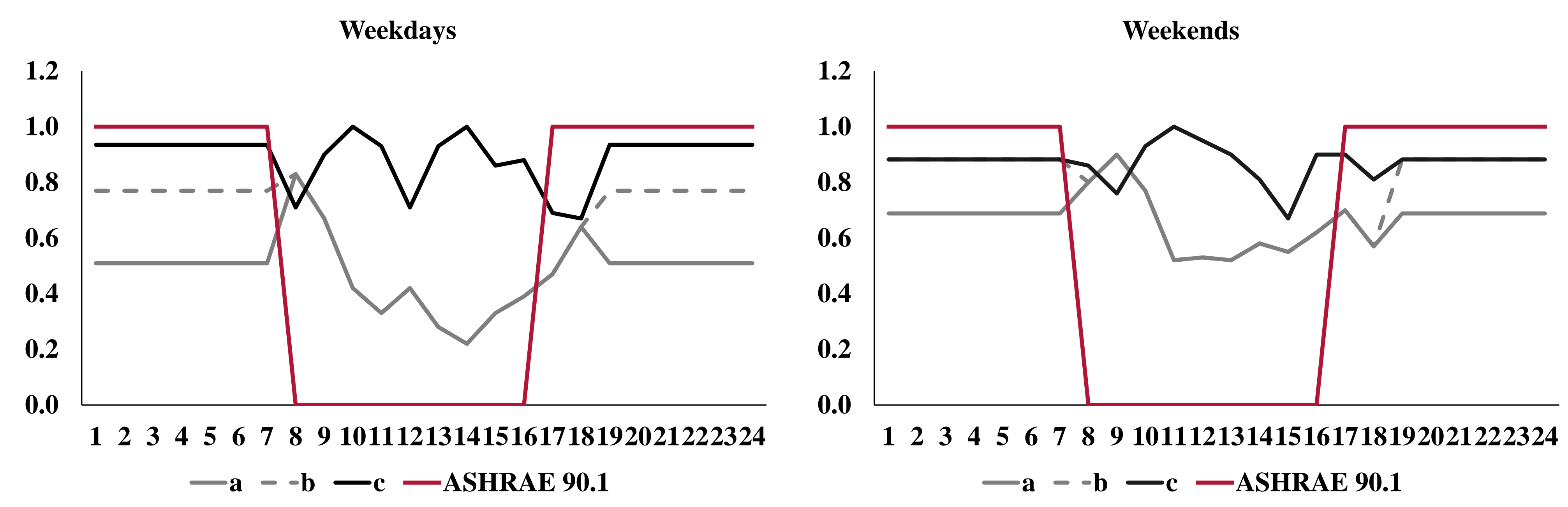

24-Hour occupancy presence schedules

Our findings verify that unique populations present behavioral patterns that do not necessarily agree with standard generic profiles. This suggests that the use of standard schedules (ASHRAE 90.1) would result in a wide gap between buildings' energy consumption predictions and actual performance.

\section{Acknowledgment:}

This work was funded by the 2016 Iowa State University Presidential Interdisciplinary Research Initiative (PIRI) on Data-Driven Science. We would like to thank Linda Shenk, Michael Dorneich, Jacklin Stonewall (ISU) and Caroline Krejci (UT Arlington) for their help with the energy use survey. 